The Third Pole: Journal of Geography

Vol. 18 - 19: 97-110, 2019

DOI: https://doi.org/10.3126/ttp.v18i0.28011

Department of Geography Education,

Central Department of Education, T.U., Kathmandu, Nepal

\title{
TOURISM EDUCATION AND TRAINING FOR THE ENTREPRENEURSHIP DEVELOPMENT
}

\section{Abstract}

\section{Narayan Prasad Paudyal, PhD $^{1}$}

This paperexplores emergingconceptsoftourismeducation, training andentrepreneurship development. Nowadays, the discourses on this theme have been growing in both developed and developing countries, especially for reducing unemployment rates through the education of youth people. For this purpose, this paper used secondary sources of data to analyze individual rationality and creativity of educated youth people for the entrepreneurship development in business sector. The analytical framework begins from the examination of tourism industry and processes for empowering those people since tourism industry is considered as one of the agents of socio-economic changes in developing countries, like Nepal. But it needs skilled and trained manpower to operate properly. The main theme of this paper is that the aforesaid manpower can be developed with entrepreneurship skills by providing education and training regarding this business. This paper entirely agrees that once the tourism industry is well run by removing hurdles seen in this sector, it can help increase employment opportunities, increase the country's revenue and solve many other social problems.

Key words: Tourism, entrepreneurship, education, training, diversity, immaturity, benefits.

\section{Background}

The United Nations World Tourism Organization (UNWTO) defined the term tourism as follows "the activities of persons traveling to and staying in places outside of their usual environment for not more than one consecutive year for leisure, business, and other purpose." Tourism includes movement from one place to another, accommodation at the place of destination, and any activities undertaken in the process (Rowe, Smith \& Borein, 2009; Andrews, 2007). Leisure activities are most commonly associated with

1 Dr. Paudyal is an Associate Professor, Department of Geography Education, Central Department of Education, Tribhuvan UniversityEmail: paudyal_narayan@yahoo.com 
for business to be the primary motivation for travel, as well as "other purposes," which may include health, education, or visiting family and friends (Rhchie, 2006).

Tourism education is an emerging concept in the field of entrepreneurship development in many developing countries, like Nepal. It provides a clear conceptual framework regarding the relationship between tourism industry and education. It helps to bring tourism industry and education interface closer to each another (Haywood \& Maki, 1992; Manhas, Manrai \& Manrai, 2016; Thapa \& Panta, 2019). Educators and employers are two major players representing a power base at the interface between education and employment (Rhchie, 2006; Andrews, 2007). According to them, educators and employers have different expectations, such as employer seeks more practical skills and their focus is on the individual's emphasis on skill transfer through education (Airey $\&$ Tribe, 2005). Contrast, the focus of educators is based on the development of more tourism-specific materials. This contrasting view creates a gap between employer and educators. It is mainly due to lack of proper communication, lack of collaboration, lack of educators' involvement in tourism industry, and lack of clear role of industry to promote education. In this context, education and training have become an emerging issue in the field of tourism industries. Therefore, they represent importance to any attempt to dissect the relationship between tourism educators and the tourism industry (Airey \& Tribe, 2005; Rhchie, 2006; Cooper \& Shepherd, 2014). In this context, the main objective of this paper is to analyze the unravel question-what is the response of employer and educators to promote entrepreneurship in tourism industry?

\section{Materials and Methods}

This paper is mainly based on secondary sources of data. Most of the information were collected from the reviews of existing literatures regarding tourism education and entrepreneurship development. Similarly, archive documents, books, journals and websites were also used. The data available from different sources are analyzed on the basis of these classification using both analytical and descriptive methods.

\section{Result and Discussion}

Tourism education and training. There is an important distinction which can, and should, be drawn between tourism education and tourism training since this will influence the type and depth of relationship which exists between industry and education (Airey \& Tribe, 2005). Training has traditionally dominated the tourism sector where vocationally-orientated courses have provided the work-force with the necessary craft skills for many years (Gracia \& Rachel, 2010). The development of training courses which aim to deliver practical knowledge and techniques has historically been linked 
Narayan Prasad Paudyal / Tourism Education and Training for the Entrepreneurship Development|| $99 \|$

to the needs of intermediaries in travel and tourism although increasingly, as industry demands a more professional workforce, the provision of these courses has expanded to embrace a much wider set of industrial sectors (Sears \& Bara, 2011; Cooper \& Shepherd, 2014).

Tourism education, on the other hand, is relatively new and remains in an early stage of its evolution. Education for tourism focuses on the process which gives an individual a set of principles and the necessary skills to interpret, evaluate and analyze i.e. it develops the critical capabilities of the student and encourages the understanding of conceptual issues in order to contribute to professional and intellectual development (Rowe, Smith \& Borein, 2009; Andrews, 2007).

Whilst training and education have evolved independently in theoretical terms, training and education in practice are heavily interwoven: in higher level education, for example, training in practical skills is seen as essential by the industry and this is reflected in the integration of an industrial year or professional stage into the majority of degree level course structures (Airey \& Tribe, 2005).

The provision of tourism education is a relatively new development and higher level courses in tourism are largely a product of the 1980s and the first half of the 1990s (Andrews, 2007). The intellectual and institutional infrastructure is, therefore, only now being put in place and the relationship between education and industry remains very much in its infancy (Cooper \& Shepherd, 2014; Rhchie, 2006; Cooper \& Westlake, 1989).

Whilst the provision and quality of training and education for tourism is being improved, the tourism industry has traditionally invested in neither (Manhas, Manrai \& Manrai, 2016). However, the late 1980s \& 1990s has seen something of a watershed for the tourism industry and the industrial and economic upheaval which has characterized the commercial climate in recent years has placed an increased emphasis on the role and importance of the human resource function in organizational survival (Airey \& Tribe, 2005; Rhchie, 2006; Gracia \& Rachel, 2010).

Key international bodies such as the World Tourism Organization (WTO), American Express, the International Labour Organization (ILO) and the World Travel and Tourism Council (WTTC) have all begun to recognize publicly the fundamental necessity of training and education to ensure a professional and productive tourism industry. 
These developments, at international level, have been complemented by an attitude change in the upper echelons of industry. For many years, training and education has not featured strongly in the culture of tourism companies - even the larger organizations have historically been hesitant about introducing comprehensive development programs - but increasingly, a more positive view is surfacing. Research undertaken by the University of Survey in 1991 suggests that the larger tourism enterprises, at least, are placing more emphasis on both training and education as companies begin to understand more fully the role of training and education in boosting company profitability, productivity and turnover (Manhas, Manrai \& Manrai, 2016).

It should be stressed, however, that whilst individual companies are "seeing the light" and recognizing the potential contribution to organizational efficiency of training and education, an appreciation of the importance of human resource development to the progression of the tourism industry as a whole is also being aroused, especially amongst the larger players in the industry, and this will be evaluated in some detail.

Tourism and entrepreneurship development. Tourism entrepreneur-ship eliminates social problems, but surge the fiscal growth and development of a country, resulting to rise in country's GDP. The tourism business has been one of the largest, fastest growing sectors in developing country like Nepal which plays as an indispensable role in job creation (Thapa \& Panta, 2019). The contribution of entrepreneurs has never been given due credit, especially in the field of tourism and yet their contribution, either good or bad have collectively been major force of shaping economic, social and cultural aspect of a place (Rowe, Smith \& Borein, 2009). Thus, the entrepreneurship in tourism has greatly contributed in development of the tourist destinations.

Therefore, the role of entrepreneurs in the development of a tourist destination came from Butler (1980) in his Destination Life Cycle model (Andrews, 2007; Shaw and Williams, 1998), "when visitors "numbers begin to increase in a destination, locals see the need to provide businesses and services to cater for the visitor's needs and the economic opportunities it provides" (Manhas, Manrai \& Manrai, 2016).

Tourism and entrepreneurship both, has been branded as indefinable and hard to measure as "there seems to be a converse relationship between the effect of entrepreneurship on tourism and the attention it has received in the tourism literature to date (Rhchie, 2006; Mathiesonnd Wall, 1982. Shaw \& Williams, 1998; Airey \& Tribe, 2005). Similarly, Gonnsen (1981) refers to entrepreneurial activity taking place early in the development life of a destination (involvement stage). However, it is outsiders who initiate the entrepreneurship process (Sears \& Bara, 2011). Barr (1990) also focused the role of 
small scale local entrepreneurial initiatives towards the growth of tourism. Snepenger, Johnson \& Rasker (1995) describe how business migration has ameliorated impacts of the stagnation phase.

Generally, the entrepreneurship profit relationship connection is empirically established, in relation to tourism in developing countries (Cooper \& Shepherd, 2014; Andrews, 2007; Shaw \& William, 1998), Echtner (1995) examined educational aspects of promoting entrepreneurship, while Din (1992) investigated the relationship between tourism and entrepreneurship in Penang Langkawi in Malaysia, Jafari (1990) has discussed sociocultural issues and the effect of entrepreneurship, Dahles and Bras (1999) highlighted a new form or entrepreneurship where indigenous men seek and compete for relationship with western female tourists (Manhas, Manrai \& Manrai, 2016). So field investigated problems of local entrepreneurship in South Pacific countries about the tension that exists between the regulators and the entrepreneurs,' Neblett (2000) investigated the indigenous entrepreneurial activities in the accommodation sector.

Most of the studies mentioned have concentrated on entrepreneurial action, Koh (1996) provided an anatomy of entrepreneurship in tourism development. He mentioned various stages in the process ie. cognitive (predisposing), orientation, opportunity search, opportunity assessment, consideration, opportunity pursuit, birth operation and evaluation (Gracia \& Rachel, 2010). In doing so, a degree of structure and logic is assumed which is unrealistic and certainly not consistent with the behavior of tourism entrepreneurs (Andrews, 2007; Russell, 2006; Rhchie, 2006)

Linkage between entrepreneurship and tourism provided by the literature is consolidated by Russell \& Faulkner (1999) where each form of entrepreneurial activity is depicted in terms of their potential bearing on the progress of Butler's (1980) model. Thus, the local entrepreneurs (Barr, 1990) are more prevalent at involvement stage, migrant entrepreneurs are found at consolidation stage, those described by Snepengeret et. al (1995) have a more significant impact at the decline or rejuvenation stage and entrepreneurial behavior such as that described by Lewis \& Green (1998) might induce turning point in the evolution of tourism at any stage throughout the cycle.

According to Faulkner (2000) there are three ways in which the tourism entrepreneur might be a change catalyst. Firstly, by shrewder management of extremely generated emergencies, he may diminish his competition. Secondly, by superior tactics he may induce crises for his competitors that render them less viable and thirdly, by excessive expansion beyond the carrying capacity and environmental sustainability limits. 


\section{Hurdles to tourism industry}

Diversity. Based on the secondary information, we have seen in National Park areas, there is no real agreement between the local government, industry and academics as to what actually constitute the tourism industry: they agree only on the fact that tourism is enormously diverse in terms of the range of sectors it encompasses and the variety of organizations it incorporates (Rowe, Smith, \& Borein, 2009; Andrews, 2007). However, in the tourism area tourism spans several industrial sectors and there are therefore differing interpretations of the categories of employment at various skill levels, and the specific needs of each sub-sector of the industry are significantly different (Cooper \& Shepherd, 2014).

In a broad interpretation of tourism its dominant sectors are seen to be accommodationrelated activities, transport in its different modes, and leisure and recreation services. There are also specialized forms of services in both the generating market (e.g. information provision) and at the destination (e.g. guiding \& events organization). Some of these activities involve the public sector as a direct provider, or otherwise in a co-coordinating role (Rhchie, 2006; Smith, 1988; Manhas, Manrai \& Manrai, 2016). The WTO's supply side classification of tourism clearly illustrates this problem (Cooper $\&$ Shepherd, 2014). The fact that tourism is interpreted in varying ways and is spread across so many sectors is reflected in the range of educational approaches and content adopted.

The problem of definition is compounded by the international nature of tourism and the different activities on which it may be based within different countries. For example, the components of the tourism industry in a developing country may be relatively simple to identify as compared to the components of the tourism industry in an industrialized nation where sophisticated segmentation techniques result in a diverse range of market niches (Cooper \& Shepherd, 2014; Rhchie, 2006). Consequently, the industry is much more complex and there are many hundreds (or thousands) of operations which are influenced by the tourism industry but which may not be obviously associated with tourism.

It is clear, therefore, that without an agreed inventory of the activities and organizations which comprise the tourism industry, it is very difficult to design training and education to fully meet those needs (Cooper \& Shepherd, 2014). With the tourism industry cutting across so many sectors and impinging upon such a wide range of operations, educators have faced with a bewildering choice of markets at which their products should be pitched (Manhas, Manrai \& Manrai, 2016). It is against this background of fragmentation that 
tourism education has developed, and it is within this framework that the relationship between education and industry must evolve.

Characteristics of the workforce. There remains, in many societies, a cultural barrier to working in the service industry: employment in service industries in general is viewed as a low status career where individuals are neither invested in nor encouraged (Rhchie, 2006; Cooper \& Shepherd, 2014). The workforce in tourism has traditionally been poorly rewarded by employers in terms of training, education and financial rewards and, as a result, the perception of tourism as an undesirable sector in which to be employed is perpetuated to cause a bad situation continue.

Most small and medium sized employers (and indeed some of the larger companies, too) fail to recognize the benefits of training and education and unsurprisingly, therefore, they do not finance these activities in a committed way (Rowe, Smith, \& Borein, 2009; Andrews, 2007). Because employees are not invested in, they commonly feel no loyalty to the organization and are more inclined to move on (Airey \& Tribe, 2005). Thus, high levels of staff turnover predominate and it is little wonder, therefore, that the characteristics of the transient and unprofessional tourism workforce do not change or improve (Andrews, 2007).

The problem is intensified by the fact that the industry is dominated by small businesses led by entrepreneurs who often possess no formal training or education in tourism. As a result, they neither recognize the need to invest heavily in training or education for their employees' self-development, nor do they recognize the benefits of such investment to their operations as a whole (Manhas, Manrai \& Manrai, 2016).

The feeling amongst those responsible for human resources in the tourism industry that there is no substitute for 'hands-on' experience and no value to training or education is one which still predominates, representing a major barrier to the development of a cooperative relationship between industry and education.

Immaturity. Many of the barriers to the implementation of full scale training and education for tourism can be attributed to the immaturity of the tourism industry international mass tourism is a relatively recent phenomenon which did not evolve until the 1950s/1960s. As a result, the tourism industry by itself remains relatively young when compared to other industries and the educational approaches which have developed to serve the industry are consequently still in their infancy. 
Tourism training has been established longer than tourism education, although by liberal estimates it is still only 50 years old. Tourism education, on the other hand, is much younger and despite the rapid progress of tourism as a subject area and the accompanying expansion in provision, the development of tourism courses at higher levels has been characterized by a lack of planning and control (Cooper \& Shepherd, 2014). This relative immaturity has been responsible for fuelling many debates relating to the quality and delivery of tourism courses and the standards of teaching (Andrews, 2007; Airey \& Tribe, 2005; Haywood, 1989) and it has also generated speculation about other issues which require consideration.

Firstly, because tourism education is such a recent addition to the academic portfolio, -it is still seeking to establish its credentials as an area worthy of serious academic study. It lacks the history and antecedents of the more mature fields and it is given trouble by conceptual weakness and fuzziness (Andrews, 2007; Cooper \& Westlake, 1989; Manhas, Manrai \& Manrai, 2016). Educators, therefore, are facing with issues and problems which are taken as real in other disciplines - for example, discussion still continues in tourism over definitions of basic terms and concepts, the equivalent of which have long since been agreed upon in other subject areas ((Airey \& Tribe, 2005; Rhchie, 2006).

As a result, the framework for tourism education is fragmented and disjointed and a clear direction for the sustained development of the subject is lacking. The integrative foundations which characterize other areas have simply not yet been developed by tourism educators and the necessary preoccupation with establishing the basis for the subject area is a distraction for those wishing to build up the 'big picture' (Andrews, 2007; Cooper \& Shepherd, 2014). Derived from this lack of an overall perspective are a number of other problems. For example, there remains an ignorance of and a lack of credibility for the subject and widespread prejudice and pre-conceptions are rife amongst academics and non-academics alike who perceive tourism as a 'soft' subject (Andrews, 2007; Cooper \& Westlake, 1989).

Secondly, the immaturity of tourism raises educational and curriculum issues which must be addressed (Gracia \& Rachel, 2010). For many years, tourism has been seen as a subject which exemplifies and enriches other disciplines and subject areas. Consequently, the body of knowledge for tourism has historically been orientated towards a nontourism application and the development of the tourism curriculum itself has therefore been impaired. Now that tourism is seeking to establish an academic pedigree in its own right, it is considerably disadvantaged. The basic foundations are missing and the 
research tools, which are sensitive to the uniqueness of tourism and which are required to progress the body of knowledge have not been fully developed and accepted.

Thirdly, the body of knowledge of tourism is constantly changing and being enhanced by research. Early attempts to chart the body of knowledge date back to publications in the early 1980s, based on research completed in the late 1970s. Jafari \& Ritchie (1981) introduced a curriculum wheel to demonstrate the elements of a centre for tourism studies, and thus courses in tourism. A few years later the British Tourism Society surveyed the industry and academics in Britain (Airey \& Nightingale, 1981) to devise a body of knowledge for tourism and the WTO has combined these two approaches into a matrix of tourism disciplines.

In 1990 Jafari categorized the body of knowledge of tourism as falling into four distinct 'platforms':

- the advocacy platform (an uncritical approach to tourism);

- the cautionary platform (focusing upon the impact of tourism upon host destinations);

- the adaptancy platform (nominating low impact forms of tourism); and

- the knowledge-based platform (advocating a more scientific, research-based approach).

Whilst these platforms are not intended to be mutually exclusive, nor evolutionary, there is a clear trend towards the knowledge-based platform in the 1990s. Each of these approaches to the body of knowledge must be incorporated into curricula, and given the changing body of knowledge, these curricula must have the in-built flexibility and ability to adopt new material.

Fourthly, the relative immaturity of tourism raises other important issues and questions for tourism educators. For example, how should tourism be approached in the classroom? What is the role of professional training? Just what should be the combination of skills development and tourism content? Does the tourism industry know what it requires of tourism at each level? What should be the balance of more general tourism education and the specific application of say, marketing, or planning and development? If a multidisciplinary programme is launched, where should it be housed- and are the institutions flexible enough to accommodate such programmes? And of crucial importance to the progress of tourism education is the resolution of the debate between the merits of tourism education and of tourism training (Airey, 2015; Rhchie, 2006; Airey \& Tribe, 2005). 
Human resource barriers to training. As the recession has taken hold internationally and major markets have gone into decline, the tourism industry finds increasingly that it has to rely on the skills, qualifications, knowledge and expertise of its managers (Cooper $\&$ Shepherd, 2014). For the larger companies where training and development programs are established, management skills will ensure a more satisfactory response to changing product and market needs. However, in smaller companies where training and education is limited or non-existent, the amateur management philosophy which predominates is likely to have left many operations in serious trouble.

The 'crisis management' techniques which have prevailed in tourism for so long are likely to lead to outmoded styles of management and instantaneous decision making driven by the needs of the moment and current operational demands (Andrews, 2007; Parsons \& Cave, 1990). This lack of planning is reflected in the human resource policies of organizations and enterprises in tourism - or rather the absence of them (Manhas, Manrai \& Manrai, 2016). The omission of suitable policies relating to human resources is one major reason why the industry has historically found it difficult to attract high caliber graduates: students considering a career in tourism are faced with the prospect of low starting salaries compared to other graduate recruiters, long hours, lack of training, limited career prospects and little recognition of prior qualifications and achievements (Rhchie, 2006; Cooper \& Shepherd, 2014). The career paths of graduates are also often unclear and as a result, quality students are inclined to look elsewhere for opportunities which offer a structured and integrated career development plan, where recruitment policies have been adapted to take into account graduates' experience in higher education (EIESP, 1991).

Without serious consideration of these issues, the tourism industry will continue to surrender the best graduates to other industrial sectors where personal development is encouraged and invested in, where structured career paths are on offer and where financial rewards are commensurate with education and experience.

The benefits of training and education. Tourism is a people-industry where the personal touch is perhaps the single most important facet of the service encounter. The quality of the human resources, therefore, is critical to the success of individual companies and to the industry as a whole. A good workforce will allow enterprises to gain a competitive advantage in the market place by adding value to the product on offer.

For the industry as a whole, therefore, the benefits of training and education are numerous. Investment in training ensures employees are equipped with the practical skills and knowledge which will not only facilitate a satisfactory service encounter, 
but will also boost the performance and productivity of the entire sector (Cooper \& Shepherd, 2014). Education on the other hand, whilst not necessarily bringing the short term measurable benefits of training, will be instrumental in the long-term in improving the quality of both service and personnel within the tourism industry (Rhchie, 2006; Andrews, 2007).

Overall, therefore, training and education will enhance the tourism product by raising the quality of personnel and infusing a sense of professionalism and ownership amongst the tourism workforce (Airey \& Tribe, 2005). It will also provide employees with a sound integrative framework, the ability to define the various sectors of tourism and the critical capabilities to understand the complex inter-relationships between them. For employers with foresight, the benefits of investing in staff development are already accruing - they are retaining staff (and reducing turnover), they are improving productivity and they are developing a more competent and professional workforce. Nevertheless, the tourism industry as a whole still lacks the vision and sagacity to invest comprehensively in training and education, continuing to perceive it as a cost rather than an investment. Brackenbury (1991) asks:

'Why is it, as I believe, if competitive advantage in service industries derived from training, do we continue to see owners and managers take the low cost route to failure?'

He continues by suggesting that many operators remain happy to employ unqualified staff, pay them poorly, fail to offer them opportunities for self-development through training and education and then wonder why their market share decreases. Brackenbury (1991) refers to this as a virtuous circle.

Clearly then, despite the benefits of a well-trained, professional tourism workforce which will deliver a better product and a higher level of service, many companies still fail to allocate resources to staff development (Gracia \& Rachel, 2010). Whilst many other industrial sectors have acknowledged the advantages of training and education for some time, the tourism industry still seems to be suffering from a 'training inertia' which is slowing the growth of the training culture desperately needed to strengthen and progress the sector (Rhchie, 2006; Cooper \& Shepherd, 2014).

However, whilst it is easy to criticize the tourism industry for not committing itself more fully to training and education, it is also easy to overlook some of the unique characteristics of tourism which are instrumental in erecting carriers to training and education, the majority of which derive from the intricate structure and nature of the amalgam of sectors referred to as the tourism industry (Rhchie, 2006). 


\section{Conclusion}

An interface between education and industry is instrumental in which without one, another can be faltering. This paper, in this manner, attempts to look for the connection between tourism education and training, and entrepreneurship development which is the significant worry of recently risen enterprise, i.e. tourism industry. A need of legitimate preparing and training is felt to guarantee an expert and gainful industry in business enterprise improvement. Instruction for the tourism industry is less paid worry among different divisions which is viewed as one of the vital zones that can wipe out poverty combining the nation's GDP. But, quantities of obstructions i.e. hurdles degrade the tourism industry to be less serious sector to do the previously mentioned activities. So, expelling the obstacles found in the tourism industry is a crucial assignment of concern individuals associated with this area. For gaining the principles of the tourism education and industry, educational programs for tourism industry, instruction ought to be fused in school level to college dimension of educational plan. Trainings for labor advancement for momentary yield, regardless of instruction which has a long impact on both nature of administration and individual, ought to be given.

\section{References}

Airey, D. (2015). 40 years of tourism studies: A remarkable story. Tourism Recreation Research, 40 (1), pp. 6-15.

Airey, D. \& Nightingale, M. (1981). Tourism occupations, career profiles and knowledge. Annals of tourism research, 8 (1), pp. 52-68.

Airey, D. \& Tribe, J. (2005). An international handbook of tourism education. United Kingdom: Elsevier.

Andrews, S. (2007). Introduction to tourism and hospitality industry, New Delhi : Tata McGraw-Hill Publishing Co,

Barr, T. (1990). From quirky islanders to entrepreneurial magnates: The transition of the Whitsundays. Journal of tourism studies, 1(2), pp. 26-32.

Brackenbury, M. (1991). Promoting destinations beyond the year 2000 opportunities and threats. In Manente, M., Cerato, M., (Eds.), From destination to destination marketing and management- designing and repositioning tourism products, CISET/University of Venice Press, Venezia, pp. 45-48.

Butler, R. W. (1980). The concept of a tourist area cycles of evolution: Implications for management of resources. Canadian Geographer, XXIV (1), pp. 5-12.

Chaskar, A. (2009). Doing research in literature and language (Researcher Companion), Pune: Vaibhav Publications 
Narayan Prasad Paudyal / Tourism Education and Training for the Entrepreneurship ...

||109\|

Cobbinah, P. B., Black, R., \& Thwaites, R. B. (2015). Biodiversity conservation and livelihoods inrural Ghana: Impacts and coping strategies. Environmental development,15, pp. 79-93.

Cooper, C. \& Shepherd, R. (2014). The relationship between tourism education and the tourism industry: Implications for tourism education. Tourism recreation research,. 22 (1).

Cooper, C. \& Westlake, J. (1989). Tourism teaching into the 1990s. Tourism management, 10, pp. 69-73.

Dahles, H. \& Bras, K. (1999). Tourism and small entrepreneurs: Development, national policy, and entrepreneurial culture: Indonesian Cases, New York: Cognizant Communication Corporation.

Echtner, C. M. (1995). Tourism education in developing nations: A three pronged approach. Tourism recreation research, 20 (2), pp.32-41.

EIESP. (1991). Education for careers in European travel and tourism. A study commissioned by the American express foundation, Paris: European Institution of Education and Social Policy.

Faulkner, B. (2000). The future ain't what it used to be: Coping with change, turbulence and disasters in tourism research and destination management. Gold Coast: Griffith University.

Gonnsen, E. (1981). The spatio-temporal development of international tourism: Attempt at a centre-periphery model. London: SAGE Publication.

Gracia, S., \& Rachel, D. (2010). Sustainable tourism in island destinations. Earthscan, London.

Haywood, K. M. (1989). Managing word-of-mouth communications. Journal of service marketing, 3 (2), pp. 55-67.

Haywood, K.M. \& Maki, K.(1992). A Conceptual model of the education/employment Interface for the Tourism Industry. In Ritchie, J. R. B, and Hawkins, D. (Eds) World travel and tourism review CAB, Oxford, pp. 237- 248.

Jafari, J. (1990). Research and scholarship: The basis of tourism education. Journal of tourism studies, 1(1), pp. 407-429.

Jafari, J. \& Ritchie, B. (1981). Towards a framework for tourism education. Annals of tourism research, 8, pp.13-33.

Koh, K. Y. (1996). The tourism entrepreneurial process: A conceptualization and implications for research and development. The tourist review, 51(4), pp. 24 41.

Lewis, R. \& Green, S. (1998). Planning for stability and managing chaos: The case of Alpine ski resorts. In: Laws, E., Faulkner, B. and Moscardo, G. (Eds). 
Embracing and managing change in tourism: International case studies. Routledge, London, pp. 138-160.

Manhas, P. S.; Manrai, L. A., \& Manrai, A. K. (2016). Role of tourist destination development in building its brand image: A conceptual model. Journal of economics, finance and administrative science. 21 (40): 1-48.

Mathieson, A. \& Wall, G. (1982).Tourism: Economic, physical and social impacts, London: Longman.

Neblett, J. (2000). Linking development, indigenous entrepreneurship and tourism, with special reference to Barbados. Geography online, 1 (2).

Parsons, D. \& Cave, P. (1990). Developing managers for tourism. London: Nedo.

Rhchie, B. W. (2006). Managing educational tourism, Viva Books Private Ltd., New Delhi, India.

Rowe, A., Smith, John D., and Borein, F. (2009). Travel and tourism, UK: Cambridge University Press

Russell, R. (2006). The contribution of entrepreneurship theory to the TALC model. In: Butler, R. (Eds.) The Tourism Area Life Cycle, Vol. 2: Conceptual and theoretical issues. Channel View Publications, Clevedon, UK, pp. 105-123.

Russell, R. \& Faulkner, B. (1999). Reliving the destination life cycle in Coolangatta: An historical perspective on the rise, decline and rejuvenation of an Australian seaside resort. In E. Laws, B. Faulkner and G. Moscardo (Eds), Embracing and managing change in tourism: International case studies (pp. 95-115). London: Routledge.

Sears, G. J. \& Bara, V. V. (2011). Toward a multistage, multilevel theory of innovation. Canadian journal of administrative sciences, 28 (4): 357-372.

Shaw, G. \& Williams, A. M. (2004). Tourism and tourism Spaces. London: SAGE Publication.

Shaw, G. \& Williams, A.M. (1998). Entrepreneurship and small business culture and tourism development. In D. Ioannides and K.G. Debbage (Eds). The economic geography of the tourist industry: A supply-side analysis, London: Routledge.

Smith, S (1988). A sense of place: place, culture and tourism. Tourism recreation research, 40 (2), pp. 220-233.

Snepenger, D. J., Johnson, J. D., \& Rasker, R. (1995). Travel-stimulated entrepreneurial migration. Journal of travel research, 34(1), pp. 40-44.

Thapa, B. \& Panta, S. K. (2019). Situation analysis of tourism and hospitality management education in Nepal. In: (ed.). Claire Liu and Heike Schänzel; Tourism education and Asia. pp. 49-62. Springer. Singapore. 